Co-occurrence of ADHD, ASD and/or learning difficulties was prevalent in $74 \%$ of cases. Age at first appointment was 16 years 10 months to 18 years 8 months. The only NICE quality standard met was discussion of transition care ideas with cares/parents. Majority had one appointment only. Repeat appointment was given to 5 patients. Outcome from clinic included discharge to GP (64\%), referral to adult mental health services (16\%), referral to Adult LD team (12\%), and review by behavioural team (8\%). Social worker involvement was recommended for all cases. All of them were seen in age banded clinic. Written transition plan was provided to all. $24 \%$ saw adult team before transfer, $14 \%$ had a key worker. $6 \%$ had a co-ordinated team. Holistic life skills training were discussed with all those who attended.

Conclusion Start of new transition clinic has facilitated transfer of Young people with neuro-developmental conditions. NICE quality standards were not met in many cases. 'Proposed beneficial features' are suggested in literature to improve outcomes; which we aspire to implement. We aim to start by providing a meeting with the adult team before transfer and providing a key worker/transition manager for all patients to achieve optimum transition.

\section{P56 HEEADSSS: STANDARDISED ASSESSMENT TO IDENTIFY PSYCHOSOCIAL ISSUES FOR UNACCOMPANIED ASYLUM SEEKING CHILDREN}

E Fillmore* ${ }^{*}$ J Slater, V Kwan. Nottingham Children's Hospital, Nottingham University Hospitals NHS Trust, Nottingham, UK

10.1136/bmjpo-2019-RCPCH-SAHM.60

Aim Unaccompanied asylum seeking children (UASC) experience psychological traumas, denying them age related cultural and developmental norms. They are at risk of significant psychosocial health problems. Identifying these health issues aids targeted interventions. This study tests feasibility of the HEEADSSS tool to identify psychosocial issues presenting at the Initial Health Assessment (IHA) for UASC.

Method 3 years of IHA reports of UASC were analysed using the HEEADSSS tool (Home \& relationships/Education/Eating/ Activities/Drugs/Sex/Self -image/harm \& depression/Safety), to identify psychosocial risks. Each UASC report was matched by age and sex with one from a non UASC young person in care.

Results IHA reports of 64 UASC and 64 matched non UASC were used. Ethnicities: UASC $48 \%$ Afghan Pashtun, 46\% Iranian Kurd. Non UASC 60\% White British, 35\% mixed Black/White British. Ages 11-18 years. Home: UASC $93 \%$ no family contact, $62 \%$ one deceased parent. Non UASC 95\% family contact, $8 \%$ one deceased parent. Education: UASC 93\% no previous formal education, $90 \%$ in UK Education with 95\% >90\% attendance, 94\% indicated a future career. Non UASC $100 \%$ previous formal education, $72 \%$ in UK education with $65 \%<80 \%$ attendance, $48 \%$ indicated a future career. Eating: UASC $6 \%$ showed disordered eating, Non UASC 32\% showed disordered eating. Activities: UASC 59\% gym, $81 \%$ music, $37 \%$ football, $83 \%$ mosque. Non UASC 35\% gym, 54\% music, $64 \%$ football. Drugs: UASC $42 \%$ cigarettes, 3\% drugs, $12 \%$ alcohol. Non UASC 27\% cigarettes, 45\% drugs, 59\% alcohol. Sex: UASC $2 \%$ sexually active, $0 \%$ previous sex education, $24 \%$ history of sexual abuse. Non UASC $38 \%$ sexually active, $100 \%$ previous sex education, $15 \%$ history of sexual abuse. Self-image/harm: UASC 2\% self harm, $61 \%$ low self esteem, $43 \%$ depression, $82 \%$ trauma history. Non UASC $45 \%$ self harm, $68 \%$ low self esteem, $38 \%$ depression, 68\% trauma history. Safety: UASC $82 \%$ felt safe, Non UASC 56\% felt safe. Overall: $87 \%$ UASC and $76 \%$ Non UASC required intervention.

Conclusion It is feasible to apply the HEEADSSS tool to the IHA report to collate specific psychosocial health risks for UASC, therefore enabling targeted interventions.

\section{P57 $\quad$ SEEN AND NOT HEARD! A QI PROJECT TO ENHANCE YOUNG PEOPLE'S VOICES IN THEIR OWN CARE}

${ }^{1}$ AM Taylor*, ${ }^{1} \mathrm{~A}$ Okereafor, ${ }^{2} \mathrm{E}$ Parish, ${ }^{1} \mathrm{G}$ Hann, ${ }^{3} \mathrm{~N}$ Davey. ${ }^{1}$ Paediatrics, North Middlesex University Hospital, London, UK; ${ }^{2}$ Paediatrics, Homerton Hospital, London, UK; ${ }^{3}$ Quality Improvement Clinic, UK

\subsection{6/bmjpo-2019-RCPCH-SAHM.61}

Aims This QI project aims to increase the number of patients aged 12-16 offered the opportunity to speak to a doctor alone when seen in the Paediatric Assessment Unit of a busy London hospital. Not only does this promote independence and autonomy, but we know that young people don't always share their problems if spoken to with their parents/carers present. Doctors therefore miss key opportunities to identify and address bullying, eating disorders, self-harm, sexual abuse and gang involvement.

Methods By creating a fishbone diagram and process mapping I formulated a list of possible interventions. I have completed two PDSA cycles thus far both of which aimed to raise awareness of good practice and signpost resources. The PDSA cycles currently being planned are: implementation of a new clerking booklet for patients aged 10-16 years old, posters aimed at young people and parents/carers normalising speaking to a doctor alone and detailing the advantages of doing so, and creation of a dedicated space to speak to young people alone. Results I am using run chart data to identify change in the proportion of young people given the opportunity to speak to a doctor alone. I have demonstrated an increase after my first two interventions but have not yet managed to sustain this change.

By completion of the project I anticipate not only an increase in the number of young people given the opportunity to speak to a doctor alone but also an increase in referrals to other services including child and adult mental health services, youth work and sexual health. Clinicians and young people will become more aware of ancillary services leading to increased access and utilisation ultimately facilitating a reduction in bullying, eating disorders, self-harm, sexual abuse and gang involvement.

Conclusion A considered and multi-faceted approach is required to ensure that doctors consistently offer young people the opportunity to speak without their parent/carer present. Even paediatric doctors lack the confidence and skills to communicate with this group of patients; revision of undergraduate and postgraduate curricula is essential to ensure these skills are developed in current and future doctors. 